Article

\title{
A Novel Index (RI) to Evaluate the Relative Stability of Soils Using Ultrasonic Agitation
}

\author{
Fakher Abbas ${ }^{1}$, Fang Lin ${ }^{2}$, Zhaolong Zhu ${ }^{1, *}$ and Shaoshan An ${ }^{1, *}$ \\ 1 State Key Laboratory of Soil Erosion and Dryland Farming on the Loess Plateau, Institute of Soil and Water \\ Conservation, Northwest A \& F University, Yangling 712100, China; sherazi@nwafu.edu.cn \\ 2 School of Control Science and Engineering, Dalian University of Technology, Dalian 116024, China; \\ linfang@mail.dlut.edu.cn \\ * Correspondence: zhu_zl@nwafu.edu.cn (Z.Z.); shan@ms.iswc.ac.cn (S.A.)
}

Citation: Abbas, F.; Lin, F.; Zhu, Z.; An, S. A Novel Index (RI) to Evaluate the Relative Stability of Soils Using Ultrasonic Agitation. Sustainability 2021, 13, 4229. https://doi.org/ $10.3390 /$ su13084229

Academic Editor: Jim Lynch

Received: 2 March 2021

Accepted: 7 April 2021

Published: 10 April 2021

Publisher's Note: MDPI stays neutral with regard to jurisdictional claims in published maps and institutional affiliations.

Copyright: (c) 2021 by the authors. Licensee MDPI, Basel, Switzerland. This article is an open access article distributed under the terms and conditions of the Creative Commons Attribution (CC BY) license (https:// creativecommons.org/licenses/by/ $4.0 /)$.

\begin{abstract}
As soil stability is a complex phenomenon, various methods and indexes were introduced to assess the strength of soils. Because of the limitations of different stability methods and indexes (including wet sieving-based), we aimed to presents a relative stability index (RI) that was based on the estimated components of the soil overall disruptive characteristic curve (SODC): (1) soil disruption constant $\left(K_{\mathrm{i}}\right.$, that is based upon dispersion energy of soils); (2) resulting change in mean weight diameter $(\triangle M W D)$. To evaluate the effectiveness and limitations of RI as well as to compare it with classical soil stability indexes of mean weight diameter (MWD) and geometric mean diameter (GMD). Ultrasonic agitation (UA) along with a wet sieving method (followed by dry sieving) was applied against four different soils named on the basis of sample location, Qingling soil (QL), Guanzhong soil (GZ), Ansai soil (AS), and Jingbian soil (JB). To evaluate the relative strength of soils at different applied energies (increase in sonication duration usually resulted in increased input energy and temperature of soil-water suspension), soils were subjected to six sonication durations $(0,30,60$, 120,210 , and $300 \mathrm{~s}$ ) with a fixed (and exact) initial amplitude and temperature. Output energy was calculated based on the amplitude and temperature of the suspension, vessel, and system. The most abrupt and maximum disruption of soil aggregates was observed at a dispersion energy level of $0-200 \mathrm{~J} \mathrm{~g}^{-1}$. The MWD value of surface and subsurface ranged between 0.58 to $0.15 \mathrm{~mm}$ and 0.37 to $0.17 \mathrm{~mm}$, respectively, while GMD was ranged from 0.14 to $0.33 \mathrm{~mm}$ overall. The results for MWD and GMD showed a similar trend. MWD and GMD showed more strong associations with physicochemical characteristics of soil than RI. A non-significant correlation was found between RI and MWD/GMD. Contrary to MWD and GMD, RI was significantly positively correlated with sand content; this finding indicated the influential role of sand in assessing the soil's relative strength. The results indicated that JB soil possessed the least MWD and GMD but proved to be relatively stable because of having the highest RI value.
\end{abstract}

Keywords: relative stability; aggregate stability; soil aggregate; ultrasonic agitation; wet sieving

\section{Introduction}

Soil aggregate stability is the soil's ability to cope with the external stresses applied to change its geometry of solid and pore spaces [1]. When the external forces dominates the internal binding forces, unstable aggregates split, eventually worsening the soil structure [2,3]. Aggregate stability is considered one of the leading quality assurance parameters of soil as it controls most of the physical, chemical and biological properties/functions of soil $[4,5]$. Because of its relationship with different soil physicochemical properties, it is somehow challenging to measure aggregate stability. Many stability methods were introduced because of the fact that soil stability is a complex phenomenon.

Along with other stability methods, wet sieving-based methods are common they are easy to use and precise. Some stability indexes, i.e., MWD and GMD, are an indication of 
soil stability but are limited to the aggregate quantity (macroaggregates). The ultrasonic agitation (UA) method is being used for decades to assess aggregate stability because of the fact that soil-water suspension could be used as a research object [6-9]. Another advantage of using ultrasonic agitation is that it can be used for soil stability assessment studies without using chemical-dispersing agents; this is particularly important when the study's objective would be to use the same soil samples for further chemical analysis [2]. Along with other merits over classical stability methods, ultrasonic agitation (UA) has an edge of providing the basis to calculate the arbitrary energy used for aggregate disruption [3]. The vital index to evaluate the rate of aggregate breakdown and dispersion is the ultrasonic energy absorbed by the soil-water suspension. Most of the ultrasonic indexes and models rely on this indicator [4]. The dispersive power is a measure of inter- and intra-aggregate bond strength, solely depending on the cementing agents' characteristics [8].

Meanwhile, some researchers consider that low ultrasonic energy is more effective for assessing the stability of various soils, especially when the objective would be to use post-sonication soil material for further biological studies [3,4], as well as macroaggregates are comparatively less resistant to low ultrasonic dispersion energy [8]. Based on the early work of North et al. [9] and Raine and So [7], many researchers calculated the output power of ultrasonic instrument with different methods by using some common parameters, i.e., sonication duration, the temperature of the soil-water suspension vessel, and acoustic power [6-10]. At the same time, Zhu et al. [11] suggested a more precise method to calculate the actual dispersion energy $\left(E_{1}\right)$ involved in soil aggregates breakdown along with energies used (lost) for heating the system $\left(E_{\mathrm{h}}\right)$, lost by instrument $(\mathrm{Ed})$ and energy lost by heating the soil-water suspension $\left(E_{\mathrm{o}}\right)$, he also added that out of $100 \%$ applied ultrasonic energy $(E)$ only about $10 \%$ of the energy $\left(E_{1}\right)$ was used for soil aggregates disruption. However, the relative stability/strength of soils is not well defined. Only a few have mentioned it in the context of the soils' comparative ability to withstand disruptive forces or the soil's ability to absorb (and eventually disrupt) energy. To assess the relative stability of soils by UA based on the applied, output, and dispersion energy (El) against respective disruptive aggregates (primary particle sizes, micro- and macroaggregates), several models and indexes have been presented, i.e., soil dispersion characteristic curve (SDCC) [9], aggregate disruption characteristic curve (ADCC) [12], aggregate liberation and dispersion curve (ALDC) [13], releasing of aggregate and dispersion curve (RADC) [14], ultrasonic soil aggregate stability (USAS) [8], ultrasonic energy (Eus) [15], ultrasonic power (Pus) [3], critical energy (Ecri) [8,16] specific energy $\left(E_{1 / 2}\right)$ [17], normalized dispersion index (NDI) [18], and b/a index [19]. All these indexes are limited to presenting either some proportion of aggregates subjected to applied or absorbed dispersion energy, i.e., clay, silt, and sand-sized particles and microaggregates or macroaggregates. Still, none used dispersion energy along with respective mean weight diameter of soils and a relative stability index that could account the relative strength of soils. This study aimed to present a soil relative stability index (RI) to estimate the relative strength of soils as well as lead to elaboration of the concept of soil aggregate hierarchy.

\section{Material and Methods}

\subsection{Soil Sampling}

To assess the stability of soils and compare different stability indexes, four different soils were collected, including (i) loamy soil from Qinling Mountains located in the south of the Loess Plateau, designated as QL; (ii) loamy soil from Shaanxi region formed on the development of Guanzhong Plain, designated as GZ; (iii) sandy soil formed from the Loess parent material the in the Ansai region, designated as AS; (iv) sandy soil collected from the Jingbian region located in the north of the Loess Plateau and the upstream area of Wuding River. Three random locations were selected for each soil, and three random samples were collected from each site at $0-20 \mathrm{~cm}$ and $20-40 \mathrm{~cm}$ depths. Hence, 72 soil samples were collected from the Loess Plateau of China between September to October 2016 (Table 1). Each soil sample was collected with an aluminum specimen box according to the principle 
of uniform sampling. The freshly excavated soil samples were gently transported to the laboratory in the aluminum specimen box, air-dried at room temperature for 15 days, and were dry-sieved to obtain $0-2 \mathrm{~mm}$ sized aggregates.

Table 1. Basic information of the sampling sites.

\begin{tabular}{|c|c|c|c|c|c|c|}
\hline Soil Sample & $\begin{array}{l}\text { Altitude } \\
\text { (m) }\end{array}$ & $\begin{array}{c}\text { Longitude } \\
\text { (E)/Latitude (N) }\end{array}$ & Slope $\left({ }^{\circ}\right)$ & Main Vegetation & Soil Type & Sampling Site \\
\hline QL & 754 & $\begin{array}{l}107^{\circ} 39^{\prime} 2.15^{\prime \prime} / \\
34^{\circ} 10^{\prime} 52.14^{\prime \prime}\end{array}$ & 42 & Oak & loamy soil & $\begin{array}{c}\text { Qinling } \\
\text { Mountains }\end{array}$ \\
\hline GZ & 549 & $\begin{array}{l}108^{\circ} 0^{\prime} 41.66^{\prime \prime} / \\
34^{\circ} 20^{\prime} 28.46^{\prime \prime}\end{array}$ & 4 & Zea mays & loamy soil & $\begin{array}{l}\text { Guanzhong } \\
\text { Plain }\end{array}$ \\
\hline AS & 1091 & $\begin{array}{l}109^{\circ} 15^{\prime} 1.66^{\prime \prime} / \\
36^{\circ} 44^{\prime} 24.54^{\prime \prime}\end{array}$ & 2 & $\begin{array}{l}\text { Sophora davidii, } \\
\text { Artemisia gmelinii, } \\
\text { Artemisia scoparia }\end{array}$ & sandy soil & Ansai \\
\hline JB & 162 & $\begin{array}{c}108^{\circ} 52^{\prime} 56.50^{\prime \prime} / \\
37^{\circ} 30^{\prime} 12.00^{\prime \prime}\end{array}$ & 2 & $\begin{array}{c}\text { Salix, wheatgrass, } \\
\text { Lespedeza, } \\
\text { Oxytropis, } \\
\text { Cleistogenes }\end{array}$ & sandy soil & Jingbian \\
\hline
\end{tabular}

QL: Qingling soil; GZ: Guanzhong soil; AS: Ansai soil; JB: Jingbian soil.

\subsection{Soil Basic Physical and Chemical Properties}

The $\mathrm{pH}$ of aggregates was measured using $\mathrm{pH}$ meter; soil organic carbon was measured using the method of dichromate oxidation [20]; extracted exchangeable cations ( $\mathrm{Mn}, \mathrm{Mg}, \mathrm{Fe}$ ) were measured by flame atomic absorption spectrophotometry (IEC 3000). The measured mechanical components was measured using a Malvern laser particle size analyzer (APA 2000).

\subsection{Aggregate Stability by Wet Sieving}

The wet-sieving method was similar to [21]. Prior to wet-sieving treatment, the soil samples were subjected to immersion for $5 \mathrm{~min}$. Later, the particle size distribution of various soils was determined with standard sieves $(1000-2000 \mu \mathrm{m}, 500-1000 \mu \mathrm{m},<250 \mu \mathrm{m})$. All fractions were oven-dried $\left(105^{\circ} \mathrm{C}\right)$ for $24 \mathrm{~h}$ to a constant weight (accuracy $0.001 \mathrm{~g}$ ). According to [22], mean weight diameter (MWD) was calculated as follows:

$$
\operatorname{MWD}=\sum_{\mathrm{i}}^{\mathrm{n}} \omega_{\mathrm{i}} \mathrm{x}_{\mathrm{i}} / \sum_{\mathrm{i}}^{\mathrm{n}} \omega_{\mathrm{i}}
$$

where $X_{i}$ is the mean diameter size of aggregate on sieve $i$ and $\omega_{i}$ is the fraction of aggregates on sieve i. Geometric mean diameter (GMD) was determined using the following equation:

$$
\mathrm{GMD}=\exp \left(\frac{\sum_{\mathrm{i}}^{\mathrm{n}} \omega_{\mathrm{i} \ln x \mathrm{i}}}{\sum_{\mathrm{i}}^{\mathrm{n}} \omega_{\mathrm{i}}}\right)
$$

\subsection{Relative Stability Index by Ultrasonic Agitation}

The ultrasonic agitation method was adopted from Zhu et al. [11] with some modifications. Two grams of oven-dried soil and $30 \mathrm{~mL}$ deionized water (soil to water ratio, 1:15) were put into a $50 \mathrm{~mL}$ beaker (i.e., $34 \mathrm{~g}$ weight). This suspension was kept for $5 \mathrm{~min}$, and the suspension was later exposed to sonication using the probe-type ultrasonic instrument UP100H (Hielscher Ultrasound Technology, Tetow, Germany), having a probe tip diameter of $10 \mathrm{~mm}$, with an amplitude of $2 \mathrm{AM}$, power density of $90 \mathrm{Wcm}^{2}$, and $20 \mathrm{kHz}$ frequency. Based on the fixed initial temperature (by three temperature sensors) and input power (amplitude), six sonication durations of 0, 30, 60, 120, 210, and $300 \mathrm{~s}$ were used to evaluate the effect of soil aggregate disruption at various energy levels (normally, applied ultrasonic power and temperature of soil-water suspension increase with increasing sonication 
duration) [2,23-25]. To differentiate various soils, dispersion energy $\left(E_{1}\right)$ was calculated as suggested by Zhu et al. [11] as follows:

$$
E_{1}=E-E_{\mathrm{D}}-E_{\mathrm{H}}-E_{\mathrm{O}}
$$

where $E$ is the input power of the ultrasonic instrument measured by the data acquisition unit; $E_{\mathrm{D}}$ is the energy consumed by the ultrasonic instrument; $E_{\mathrm{H}}$ is the energy of heating the vessel, water, and soil; and $E_{\mathrm{O}}$ is the energy not used in heating and dispersing the soil, which includes the mechanical loss and heat loss by conduct in the soil-water system. After each agitation step, different soil fractions were determined using a particle size analyzer (APA 2000). A new soil disruption model, soil overall disruption curve (SODC), was used to formulate the relative stability index (RI). Similar with aggregate disruption characteristic curve (ADCC) supposed by Tippkötter. (1994) [12], the SODC modeled the change of soil's MWD $(M)$ under dispersion energy by the following relationship:

$$
M=M_{\mathrm{C}}+D e^{-K_{\mathrm{i}} E}
$$

where, $M_{C}$ is the MWD of soil when all aggregates are dispersed into primary particle (i.e., sand, silt and clay) and $D$ is the change of MWD (i.e., $\triangle \mathrm{MWD}$ ) during aggregate disruption with the rate constant $\left(K_{\mathrm{i}}\right)$ of dispersion energy. Then, the rate of changing MWD of soil during aggregate disruption by ultrasonic energy is

$$
\frac{d M}{d E}=D K_{\mathrm{i}} e^{-K_{\mathrm{i}} E}
$$

The highest disruption rate is subjected to $E=0$, which indicates the weakest point of soil aggregate and illustrates the present ability of soil aggregate against dispersion. Thus, the relative stability of soil aggregates (RSA, $\mathrm{g} \mathrm{mm} \mathrm{J}^{-1}$ ) and the relative stability Index of soil (RI, $\mathrm{J} \mathrm{g}^{-1} \mathrm{~mm}^{-1}$ ) could be as follows:

$$
\begin{aligned}
& \mathrm{RSA}=D K_{\mathrm{i}} \\
& \mathrm{RI}=1 / \mathrm{RSA}
\end{aligned}
$$

The lower RI is, the larger the RSA is, i.e., the higher the aggregate dispersion under per unit energy (E) applied and thus, weaker the resistant ability of soil against breakdown would be. Here, RSA is linear with $D$, indicating that large soil aggregates could disrupt more easily than smaller ones because less cohesive forces among aggregates by binding agent exist. It is considered that inter-aggregate bonding is weaker than intra-aggregate. In general, we assume that the higher the RI of a given soil, the more relatively stable the soil would be.

\subsection{Statistical Analysis}

Statistical analyses were performed using the R 3.4.2 software package for Windows. One-way ANOVA testing was applied to determine the significant difference among the soils with a 0.05 significance level. All figures were designed using Origin 6 software. Person's correlation was performed to identify the relationship between stability indexes and physical properties of soil.

\section{Result}

\subsection{Soil Basic Physical and Chemical Properties}

The physical and chemical properties of soils are presented in Table 2. On the surface, the soil $\mathrm{pH}$ ranged from 7.12 to 8.98 , and increased in the order of $\mathrm{QL}<\mathrm{GZ}<\mathrm{AS}<\mathrm{JB}$, while for the subsurface, the lowest recorded $\mathrm{pH}$ was 6.34 , which is acidic. The SOM content of soils increased in the order of $\mathrm{JB}<\mathrm{AS}<\mathrm{QL}<\mathrm{GZ}$ for surface, and while overall subsurface soils had less organic matter content than surface soil, QL soil had the highest SOM content 
for both layers. Generally, the $\mathrm{Mn}, \mathrm{Mg}$, and Fe contents of studied soils were in the range of 0.21 to $0.62,6.56$ to 11.43 , and 8.64 to 19.48 , respectively. As a whole, QL soil possessed the highest exchangeable $\mathrm{SOM}, \mathrm{Mn}, \mathrm{Mg}$, and Fe with the least $\mathrm{pH}$. The JB soil had the highest sand content among all of the soils.

Table 2. Physical and chemical properties of soil samples.

\begin{tabular}{|c|c|c|c|c|c|c|c|c|c|}
\hline \multirow{2}{*}{$\begin{array}{c}\text { Soil } \\
\text { Sample }\end{array}$} & \multirow{2}{*}{$\begin{array}{l}\text { Depth } \\
\text { (cm) }\end{array}$} & \multirow{2}{*}{$\mathrm{pH}$} & \multirow{2}{*}{$\begin{array}{c}\text { SOM } \\
(\%)\end{array}$} & \multicolumn{3}{|c|}{ Exchangeable Cations (g/Kg) } & \multirow{2}{*}{ Clay (\%) } & \multirow{2}{*}{ Silt $(\%)$} & \multirow{2}{*}{ Sand $(\%)$} \\
\hline & & & & Mn & $\mathrm{Mg}$ & $\mathrm{Fe}$ & & & \\
\hline \multirow[t]{2}{*}{ QL } & $0-20$ & $7.12 \pm 0.46 \mathrm{~B}$ & $1.86 \pm 0.26 \mathrm{~A}$ & $0.62 \pm 0.04 \mathrm{~A}$ & $11.43 \pm 5.61 \mathrm{~A}$ & $19.26 \pm 3.2 \mathrm{~A}$ & $24.37 \pm 3.0 \mathrm{~A}$ & $33.95 \pm 1.66 \mathrm{~A}$ & $41.68 \pm 4.64 \mathrm{C}$ \\
\hline & $20-40$ & $6.34 \pm 0.29 c$ & $1.59 \pm 0.58 \mathrm{a}$ & $0.46 \pm 0.03 \mathrm{a}$ & $9.78 \pm 1.42 \mathrm{a}$ & $19.48 \pm 3.9 \mathrm{a}$ & $23.75 \pm 0.33 \mathrm{a}$ & $33.98 \pm 1.71 \mathrm{a}$ & $42.26 \pm 1.50 \mathrm{c}$ \\
\hline \multirow[t]{2}{*}{ GZ } & $0-20$ & $8.51 \pm 0.06 \mathrm{~A}$ & $1.26 \pm 0.50 \mathrm{~B}$ & $0.35 \pm 0.17 \mathrm{~B}$ & $6.87 \pm 4.61 \mathrm{C}$ & $9.81 \pm 2.4 \mathrm{BC}$ & $24.69 \pm 2.35 \mathrm{~A}$ & $32.68 \pm 0.74 \mathrm{~A}$ & $42.62 \pm 3.08 \mathrm{C}$ \\
\hline & $20-40$ & $8.56 \pm 0.11 \mathrm{a}$ & $1.45 \pm 0.31 \mathrm{~b}$ & $0.46 \pm 0.00 \mathrm{a}$ & $7.82 \pm 3.83 c$ & $14.38 \pm 9.4 b$ & $25.39 \pm 1.13 \mathrm{a}$ & $33.58 \pm 0.72 \mathrm{a}$ & $41.02 \pm 1.81 \mathrm{c}$ \\
\hline \multirow[t]{2}{*}{ AS } & $20-40$ & $8.93 \pm 0.03 \mathrm{~A}$ & $0.89 \pm 0.43 \mathrm{C}$ & $0.33 \pm 0.04 \mathrm{~B}$ & $9.21 \pm 2.33 \mathrm{~B}$ & $14.44 \pm 1.9 \mathrm{~B}$ & $7.64 \pm 0.77 \mathrm{C}$ & $18.27 \pm 0.94 \mathrm{~B}$ & $69.72 \pm 1.64 \mathrm{~B}$ \\
\hline & $20-40$ & $8.89 \pm 0.10 \mathrm{a}$ & $0.54 \pm 0.13 c$ & $0.33 \pm 0.04 b$ & $9.56 \pm 1.41 \mathrm{a}$ & $12.55 \pm 3.9 c$ & $11.97 \pm 0.33 b$ & $18.57 \pm 1.17 b$ & $69.44 \pm 1.50 \mathrm{~b}$ \\
\hline \multirow[t]{2}{*}{ JB } & $0-20$ & $8.98 \pm 0.07 \mathrm{~A}$ & $1.60 \pm 0.18 \mathrm{AB}$ & $0.21 \pm 0.08 \mathrm{C}$ & $6.56 \pm 2.87 \mathrm{C}$ & $9.75 \pm 3.6 \mathrm{BC}$ & $12.01 \pm 1.21 \mathrm{~B}$ & $8.80 \pm 1.47 \mathrm{C}$ & $83.55 \pm 2.50 \mathrm{~A}$ \\
\hline & $20-20$ & $8.93 \pm 0.46 \mathrm{a}$ & $0.53 \pm 0.19 \mathrm{c}$ & $0.23 \pm 0.02 c$ & $8.2 \pm 1.12 b c$ & $8.64 \pm 2.6 \mathrm{~d}$ & $6.48 \pm 1.31 c$ & $8.08 \pm 2.36 c$ & $85.43 \pm 3.66 \mathrm{a}$ \\
\hline
\end{tabular}

SOM: soil organic matter; pH: pH of the soil; Mn: manganese; Mg: magnesium; Fe: iron. QL, Qingling soil; GZ, Guanzhong soil; AS, Ansai soil; JB, Jingbian soil. Different uppercase $(\mathrm{A}-\mathrm{C})$ and lowercase $(\mathrm{a}-\mathrm{c})$ letters indicate significant differences among the surface and subsurface soils, respectively, at the significance level of 0.05 . Mean \pm standard deviation $(n=9)$.

\subsection{Aggregate Stability Assessment by Wet Sieving}

The MWD and GMD results are presented in Figure 1. As a whole, QL soil possessed the highest while JB soil least MWD and GMD values at both surfaces, the MWD and GMD trends for all the four soils were similar at both depths. The MWD and GMD order of surface and subsurface soils were as follows: QL $>$ GZ > AS > JB. Overall, MWD of surface and subsurface ranged between 0.58 to $0.15 \mathrm{~mm}$ and 0.37 to $0.17 \mathrm{~mm}$, respectively, while GMD ranged from 0.33 to $0.14 \mathrm{~mm}$ at both depths.
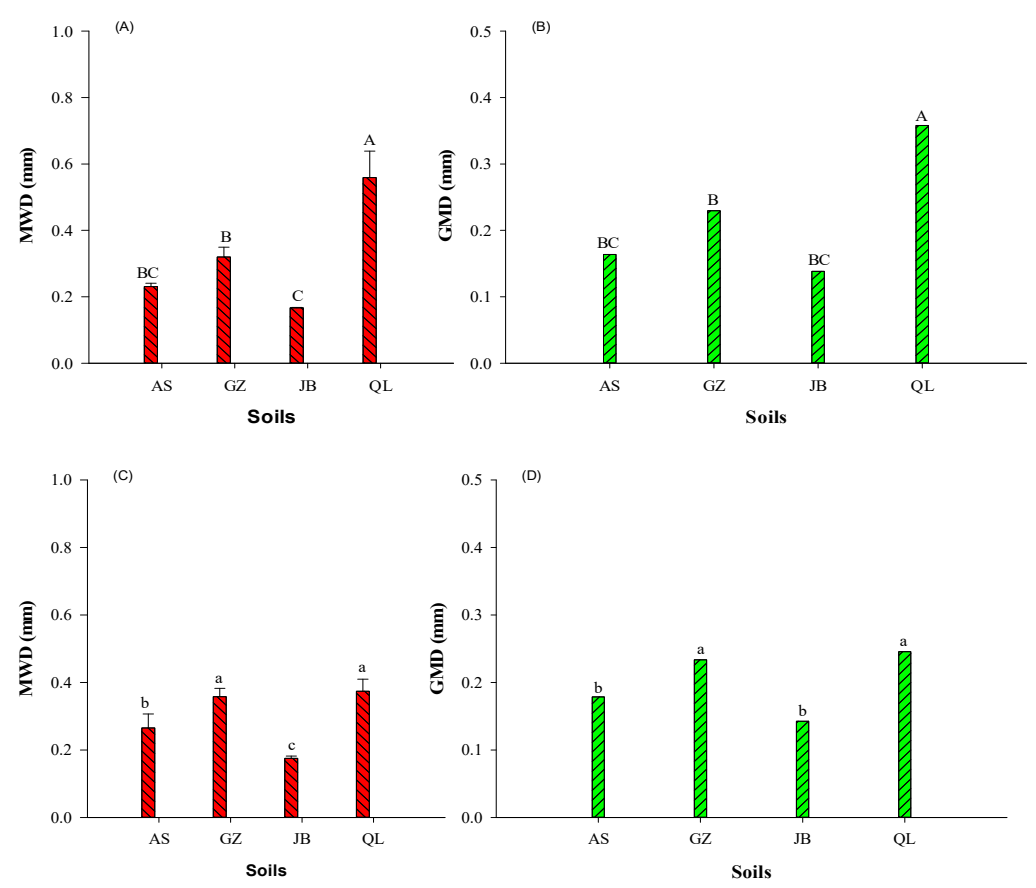

Figure 1. Mean weight diameters (MWD) and geometric mean diameter (GMD) $(\mathbf{A}, \mathbf{B})$ at $0-20 \mathrm{~cm}$ and $(C, D)$ at $20-40 \mathrm{~cm}$ levels by wet sieving method. Different uppercase $(A-C)$ and lowercase $(a-c)$ letters indicate significant differences among the surface $(0-20 \mathrm{~cm})$ and subsurface soils $(20-40 \mathrm{~cm})$, respectively, at the significance level of $0.05(n=9)$.

\subsection{Soil Overall Disruption Curve (SODC)}

The soil overall disruption curve (SODC) showed a clear disruption trend for different soils along with dispersion energy (Figure 2A,B). The MWD of soil decreased parallel 
to the dispersion energy (more macroaggregates converted into microaggregates and eventually to primary particles) until soils gained a stable condition (no more or very minute dispersion) with the increase of dispersion energy. There was a visible difference of trend between the surface and subsurface soils, in which surface soils were more discriminated than subsurface and at surface depth compared to others, the MWD of QL soil gradually decreased with dispersion energy level and hence showed a smoother curve than other soils, and the QL soil was left with more macroaggregates (more MWD) after the final $300 \mathrm{~s}$ ultrasonication. Overall, the maximum dispersion of soil (abrupt change in MWD) was observed at $30 \mathrm{~s}$ ultrasonication or between $0-200 \mathrm{~J} \mathrm{~g}^{-1}$ dispersion energy. It could be observed that the MWD of JB was least changed (less aggregate disruption, less $K_{\mathrm{i}}$ ) and close to its stable state (Figure 2A). The MWD value of four surface soils ranged from 0.58 to $0.07 \mathrm{~mm}$. At the subsurface layer, SODC showed no visible distinction between different soils. However, GZ and QL soils initially had the highest MWD (more macroaggregates, $0.39 \mathrm{~mm}$ ) than other soils, but they ended up with a similar trend as the rest of the soils (Figure 2B). The estimated parameters for the SODC as a function of ultrasonic dispersion energy are presented in Table 3 . The $M_{\mathrm{C}}$ factor ranged between $0.038 \mathrm{~mm}$ and $0.202 \mathrm{~mm}$, and $0.041 \mathrm{~mm}$ and $0.094 \mathrm{~mm}$ for surface and subsurface soils, respectively; QL soil had the highest $M_{\mathrm{C}}$ value among all of the soils, indicating a soil with largest amount of macroaggregates initially. The dispersive constant $\left(K_{\mathrm{i}}\right)$ represents the disruption rate of soils; AS was the least while JB was the most relative stable soil among the four soils, with the least $K_{\mathrm{i}}$. At the top surface, the $K_{\mathrm{i}}$ of AS was highest while that of QL soil was the least, with the order as follow: $\mathrm{QL}<\mathrm{JB}<\mathrm{GZ}<\mathrm{AS}$. The order of $K_{\mathrm{i}}$ for subsurface soils was JB $<$ QL $<$ GZ $<$ AS.
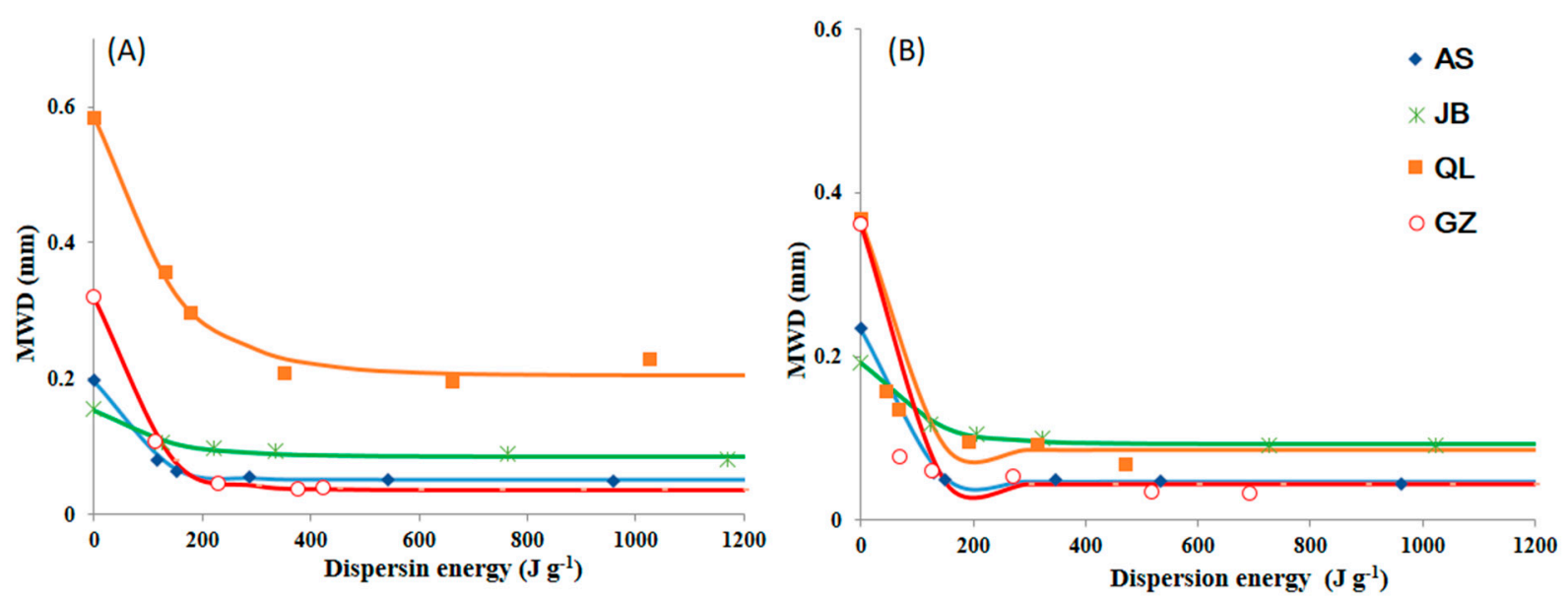

Figure 2. The soil overall disruption curve (SODC) of different $(A)$ surface soils $(0-20 \mathrm{~cm})$ and (B) subsurface soils (20-40 cm). MWD, mean weight diameter; QL, Qingling soil; GZ, Guanzhong soil; AS, Ansai soil; JB, Jingbian soil.

Table 3. Estimated parameters for the models of aggregates distribution as a function of applied ultrasonic energy at surface and subsurface soil layers.

\begin{tabular}{|c|c|c|c|c|c|c|c|}
\hline & & $0-20 \mathrm{~cm}$ & & & $20-40 \mathrm{~cm}$ & & \\
\hline Soil Sample & $M_{\mathrm{C}}(\mathrm{mm})$ & $D(\mathrm{~mm})$ & $K_{\mathrm{i}}\left(\mathrm{g} \mathrm{J}^{-1}\right)$ & Soil Sample & $M_{\mathrm{C}}(\mathrm{mm})$ & $D(\mathrm{~mm})$ & $K_{\mathrm{i}}\left(\mathrm{g} \mathrm{J}^{-1}\right)$ \\
\hline AS & 0.050 & 0.147 & 0.020 & AS & 0.048 & 0.187 & 0.094 \\
\hline JB & 0.085 & 0.069 & 0.010 & JB & 0.094 & 0.098 & 0.015 \\
\hline QL & 0.202 & 0.382 & 0.008 & QL & 0.089 & 0.494 & 0.018 \\
\hline$\overline{G Z}$ & 0.038 & 0.282 & 0.015 & $\mathrm{GZ}$ & 0.041 & 0.457 & 0.021 \\
\hline
\end{tabular}

QL, Qingling soil; GZ, Guanzhong soil; AS, Ansai soil; JB, Jingbian soil; A: mass fraction; D: change of Mean weight diameter; $K_{\mathrm{i}}$ : dispersion constant. 


\subsection{Relative Stability Index (RI)}

The relative stability index (RI) of fours soils was present in Table 4. JB soil had the highest RI value at the surface and subsurface soils, which was 4-5 times greater than other studied soils. Increasing orders of RI for surface and subsurface soils were as follows: $\mathrm{JB}>\mathrm{QL}>\mathrm{AS}>\mathrm{GZ}$ and JB $>\mathrm{AS}>\mathrm{QL}>\mathrm{GZ}$, respectively. There was a noticeable difference in RI value between the surface and subsurface soils $(p<0.05)$. As a whole, the RI value of JB soil was 4-6 times higher than other three soils.

Table 4. Relative stability index (RI) of four soil at $0-20 \mathrm{~cm}$ and $20-40 \mathrm{~cm}$ layers.

\begin{tabular}{|c|c|c|c|}
\hline & $0-20 \mathrm{~cm}$ & & $20-40 \mathrm{~cm}$ \\
\hline Soils & $\mathrm{RI}\left(\mathrm{J} \mathrm{g}^{-1} \mathrm{~mm}^{-1}\right)$ & Soils & $\mathrm{RI}\left(\mathrm{J} \mathrm{g}^{-1} \mathrm{~mm}^{-1}\right)$ \\
\hline AS & $411.61 \pm 14.03 \mathrm{~B}$ & AS & $162.72 \pm 26.06 b$ \\
\hline JB & $1612.95 \pm 86.35 \mathrm{~A}$ & $\mathrm{JB}$ & $736.32 \pm 38.57 \mathrm{a}$ \\
\hline QL & $328.48 \pm 10.90 \mathrm{BC}$ & QL & $126.71 \pm 3.94 \mathrm{bc}$ \\
\hline $\mathrm{GZ}$ & $245.75 \pm 21.898 \mathrm{C}$ & $\mathrm{GZ}$ & $103.70 \pm 3.48 c$ \\
\hline
\end{tabular}

QL, Qingling soil; GZ, Guanzhong soil; AS, Ansai soil; JB, Jingbian soil. Different uppercase (A-C) and lowercase $(\mathrm{a}-\mathrm{c})$ letters indicate the significant differences among the surface and subsurface soils, respectively, at the significance level of 0.05 . RI, relative stability index. Mean \pm standard deviation $(n=9)$.

\subsection{Correlation Analysis}

RI was positive correlated with sand content $(\mathrm{r}=0.72)$ and negative correlated with silt content $(\mathrm{r}=-0.74)$ at a significant level of $p<0.05$, but was not in significant correlation with MWD and GMD (Table 5). The MWD was highly positive, correlated with SOM, silt, and Mn content $(r=0.94, r=0.85, r=0.97$, respectively) while significantly negatively correlated with sand content $(\mathrm{r}=-0.84)$ at a significant level of $p<0.01$. GMD was significantly positive correlated with clay, silt, $\mathrm{Mn}$, and SOM contents $(\mathrm{r}=0.82, \mathrm{r}=0.83$, $p<0.01, \mathrm{r}=0.95, \mathrm{r}=0.97$, respectively). A strong significant positive correlation was observed between MWD and GMD $(r=0.99)$ at a significant level of $p<0.01$.

Table 5. Correlations of stability indexes (RI, MWD, GMD) with each other as well as with soil physicochemical properties.

\begin{tabular}{cccccccccc}
\hline & Clay & Silt & Sand & SOM & pH & Mn & Mg & Fe & RI \\
\hline RI & -0.68 & $-0.74^{*}$ & $0.72^{*}$ & -0.43 & 0.41 & -0.64 & -0.51 & -0.51 & 1 \\
MWD & $0.83^{*}$ & $0.85^{* *}$ & $-0.84^{* *}$ & $0.94^{* *}$ & $-0.74^{*}$ & $0.97^{* *}$ & 0.67 & $0.84^{* *}$ & -0.57 \\
GMD & $0.82^{*}$ & $0.83^{*}$ & $-0.83^{*}$ & $0.97^{* *}$ & $-0.74^{*}$ & $0.95^{* *}$ & 0.63 & $0.80^{*}$ & -0.52 \\
\hline
\end{tabular}

SOM: soil organic matter; pH: $\mathrm{pH}$ of the soil; Mn: manganese; Mg: magnesium; Fe: iron; MWD, mean weight diameter; GMD, geometric mean diameter; RI, relative index. * significant level at $p<0.05$; ** significant level at $p<0.01$.

\section{Discussion}

\subsection{Relationship between Stability Indexes and Basic Soil Parameters}

Cementing material, including soil organic matter, were found to be the main inflectional factors affecting soil aggregate stability [26-29]. Still, these studies were based on the size and quantity of aggregates (MWD, GMD) rather than actual dispersion energy calculations (qualitative analysis). The present study also indicates a strong positive correlation of MWD and GMD with SOM (Table 5). Contrary to the MWD and GMD, there was a non-significance week negative correlation between SOM and RI, indicating that RI is not influenced much by SOM (Table 5). Along with other factors, many studies indicated the importance of clay as a binding agent for soil strength; clay is the primary textural component and acts as a binding agent, affecting the soil structure, aggregate formation, and the aggregate relative strength of soils [26]. Clay particles are vital for aggregate formation. A minimum of $15 \%$ is needed to maintain the strength of soils [27]. Clay concentration physically affects aggregation through swelling and dispersion [28]. Clay particles are a vital element for relatively stable soil aggregates and, hence, soils [29]. Soil textural 
primary particles (sand, silt, clay) also influence the relative strength of soil aggregates; for instance, clay particles act as major binding agents along with other cementing agents and determine the relevant/comparative strength of aggregates/soils [30]; these results are in accordance with our MWD and GMD values while contrasting with RI, as there was non-significant correlations of clay with MWD, GMD, and RI. Many studies have indicated the negative effect of sand content on soil aggregates' quantitative stability [31]. In this study, we found a significantly positive correlation of RI with sand content; the more sand content contained in a soil, the more relatively stable the soil (more qualitative stability). JB soil possessed the highest amount of sand content and was the most relatively stable soil among all soils; these findings are consistent with some studies that emphasize the positive effect of sand on the relative strength of soils $[32,33]$. This positive effect of sand on soil relative stability indicates RI is a more unique and novel index. The present correlation results indicate that RI is more dependent on sand content than SOM; this could be because sand content absorbs more energy but is resistant against breakdown. Hence soils with high sand content were relatively more stable than soils with low sand content. Overall, the results of the RI index indicate that topsoil was more stable than subsurface soil $(p<0.05)$. The MWD/GMD results of subsurface soils revealed no significant difference between AS and JB soils $(p<0.05)$.

\subsection{Comparative Approach of RI with Other Stability Indexes}

Previously, many researchers introduced soil stability indexes based on the macroand microaggregates quantities as well as on the medium of application, i.e., MWD, GMD, K index (erodibility), MWAD (mean weight aggregate diameter), RSI (relative slaking index), FW (fast wetting), WS (wet stirring), SW (slow wetting), and RMI (relative mechanical breakdown) [32]. Many researchers believe that MWD and GMD are effective soil stability assessment tools, and higher values of these indexes are signs of highly stable soils [33]. Still, they all rely on quantitative aggregate measurements and lack the concept of arbitrary energy measurement. Although none have defined relative stability, many researchers used this in the comparative strength of soil aggregates, i.e., the relative stability macroaggregates is less than that of microaggregates $[9,27]$. Two major stability indexes, MWD and GMD, also had limitations, i.e., if the soil contains a high quantity of macroaggregates, it eventually ended up with high MWD and, hence, higher macro stability [34]. This study was in accordance with our results for MWD and GMD (Figure 1), where MWD and GMD values of QL soil were highest because they possessed more $>0.25 \mathrm{~mm}$ sized aggregate (macroaggregates) than other soils. Similarly, results of MWD indicated that all soils fall in the unstable category according to the stability classification system based on Le Bissonnais [35], and this could be because of the fact that we use different aggregate size fractions than recommended for wet sieving $(0.05$ to $>5 \mathrm{~mm})$. We also observed that WSDC (Figure 2A,B) showed a similar trend of macroaggregates as by MWD and GMD, and QL soil, being the richest source of macroaggregates, had high MWD value initially (at $0 \mathrm{~s}$ ) and finally (at $300 \mathrm{~s}$ ), indicating QL soil was more stable than all other soils with respect to MWD values, but from the dispersion point of view, the change in the MWD of QL soil was higher than the JB soil that reached its stable state more quickly (less dispersion \%) than QL soil (Figure 2B) at 0-20 cm depth of QL soil, initial MWD was $0.58 \mathrm{~mm}$ while final MWD was $0.18 \mathrm{~mm},>60 \%$ dispersion rate/change in aggregate \%). In comparison, JB soil dispersed about $35 \%$ of its aggregates and achieved a stable state. This was also verified by the RI value of different soils (Table 4), where RI (eventually the relative strength) of JB soil was higher than all others including QL soil; this was because of the fact that JB soil reached its stable state abruptly after minute disruption. We observed that sand content absorbs more energy but disperses less, and this is another reason behind the high relative stability of JB soil. There are many positive aspects of using this index for relative stability-based studies: (1) It accounts for the dispersion energy and resulting aggregate sizes and quantity (particle size diameter, PSD, and MWD). (2) RI did not significantly correlate with MWD and GMD, indicating RI is a unique index compared 
to other stability indexes based on aggregate size and quantity. (3) RI could be evaluated using macroaggregate and microaggregate fractions, and it can account for the complete soil disruption (MWD) and dispersion energy used for breakdown to be used for in-depth soil stability assessments. (4) RI is significantly positively correlated with sand content, but there was a non-significant relationship between RI and SOM; this provides a new dimension when evaluating soils based not just on organic contents (binding agents), such that even if all soils absorb an almost similar amount of energy, some still achieved stability more abruptly than others, so provides an actual definition of soils' relative stability. (5) RI proved to be a better index than MWD/GMD based on the results as there was prominent difference $(p<0.05)$ between different soils that had different soil characteristics (OM, texture) (Table 4). Although RI is precise, there are some limitations of using this index as well. (1) Precise equipment (ultrasonicator) is required to calculate the energy values; some researchers found a 10-20\% error for ultrasonic soil stability results [36]. (2) RI is more associated with the textural component (sand) rather than binding agents (SOM). Despite of some limitations, we recommend RI as an index for relative stability assessment of soils that is not only based on MWD but also accounts for the dispersion energy to disperse soils at various ultrasonic intervals for in-depth study.

\section{Conclusions}

As indexes of soil stability, the MWD and GMD were positive with SOM content, and negative with sand content at a significant level of $p<0.01$. The MWD value of surface and subsurface soils investigated ranged between 0.58 to $0.15 \mathrm{~mm}$ and 0.37 to $0.17 \mathrm{~mm}$, respectively, while GMD was ranged from 0.14 to $0.33 \mathrm{~mm}$ overall. The most abrupt and maximum disruption of soil aggregates investigated was observed at a dispersion energy level of $0-200 \mathrm{~J} \mathrm{~g}^{-1}$. The relative stability index of soil, RI is based on the change in MWD in line with the applied dispersion energy. Among the four soils investigated, JB soils had a largest RI, about $1613 \mathrm{~g} \mathrm{~J}^{-1} \mathrm{~mm}^{-1}$ for surface soil and $736 \mathrm{~g} \mathrm{~J}^{-1} \mathrm{~mm}^{-1}$ for subsurface soil, and GZ had a smallest RI by about $245 \mathrm{~g} \mathrm{~J}^{-1} \mathrm{~mm}^{-1}$ for surface soil and $104 \mathrm{~g} \mathrm{~J}^{-1} \mathrm{~mm}^{-1}$ for subsurface soil, separately. RI was found to be significantly positively correlated with sand content, but not significantly correlated with SOM content. Further research is required to explore the universal applicability of RI for the soils. (see Supplementary Materials).

Supplementary Materials: The following are available online at https://www.mdpi.com/article/10 .3390/su13084229/s1: Table S1—Correlation analysis of soil intra-characteristics.; Excel S1—examples.

Author Contributions: Conceptualization, Z.Z.; Methodology, F.A., F.L., and Z.Z.; Software, F.A. and Z.Z.; Validation, F.A. and Z.Z.; Formal analysis, F.A. and F.L.; Investigation, F.A. and F.L.; Resources, F.L., Z.Z. and S.A.; Data Curation, F.A. and F.L.; Writing-original draft preparation, F.A.; Writing-review and editing, F.A., Z.Z. and S.A.; Visualization, F.A. and F.L.; Supervision, S.A.; Project administration, Z.Z.; Funding acquisition, Z.Z. All authors have read and agreed to the published version of the manuscript.

Funding: This research was funded by National Natural Science Foundation of China (NSFC No. 41771317).

Institutional Review Board Statement: Not applicable.

Informed Consent Statement: Not applicable.

Data Availability Statement: Not applicable.

Conflicts of Interest: The authors declare no conflict of interest.

\section{References}

1. Díaz-Zorita, M.; Perfect, E.; Grove, J.H. Disruptive methods for assessing soil structure. Soil Tillage Res. 2002, 64, 3-22. [CrossRef]

2. Mayer, H.; Mentler, A.; Papakyriacou, M.; Rampazzo, N.; Marxer, Y.; Blum, W.E.H. Influence of vibration amplitude on the ultrasonic dispersion of soils. Int. Agrophysics 2001, 16, 53-60.

3. Schomakers, J.; Mentler, A.; Steurer, T.; Klik, A.; Mayer, H. Characterization of soil aggregate stability using low intensity ultrasonic vibrations. Int. Agrophysics 2011, 25, 165-172. 
4. Mentler, A.; Schomakers, J.; Mayer, H. Low intensity ultrasonic vibration amplitude as a tool for characterisation water stable soil aggregates. In Proceedings of the EGU General Assembly, Vienna, Austria, 7-12 April 2013.

5. Schomakers, J.; Mentler, A.; Degischer, N.; Blum, W.E.H.; Mayer, H. Measurement of soil aggregate stability using low intensity ultrasonic vibration. Span. J. Soil Sci. 2011, 1, 8-19. [CrossRef]

6. Schomakers, J.; Zehetner, F.; Mentler, A.; Ottner, F.; Mayer, H. Study of soil aggregate breakdown dynamics under low dispersive ultrasonic energies with sedimentation and X-ray attenuation. Int. Agrophysics 2015, 29, 501-508. [CrossRef]

7. Raine, S.R.; So, H.B. An energy based parameter for the assessment of aggregate bond energy. J. Soil Sci. 1993, 44, 249-259. [CrossRef]

8. Mentler, A.; Mayer, H.; Strauß, P.; Blum, W.E.H. Characterisation of soil aggregate stability by ultrasonic dispersion. Int Agrophysics 2004, 18, 39-45.

9. North, P.F. Towards an Absolute Measurement of Soil Structural Stability Using Ultrasound. Eur. J. Soil Sci. 1976, 27, 451-459. [CrossRef]

10. Lin, S.; Zhang, F. Measurement of ultrasonic power and electro-acoustic efficiency of high power transducers. Ultrasonics 2000. [CrossRef]

11. Zhu, Z.L.; Minasny, B.; Field, D.J. Adapting technology for measuring soil aggregate dispersive energy using ultrasonic dispersion. Biosyst. Eng. 2009, 104, 258-265. [CrossRef]

12. Tippkotter, R. The effect of ultrasound on the stability of mesoaggregates $(60-2000 \mu \mathrm{m})$. Zeitschrift für Pflanzenernährung und Bodenkunde 1994. [CrossRef]

13. Field, D.J.; Minasny, B. A description of aggregate liberation and dispersion in A horizons of Australian Vertisols by ultrasonic agitation. Geoderma 1999, 91, 11-26. [CrossRef]

14. Ribeiro, B.T.; de Lima, J.M.; Curi, N.; de Oliveira, G.C. Aggregate breakdown and dispersion of soil samples amended with sugarcane vinasse. Sci. Agric. 2013, 70, 435-441. [CrossRef]

15. Schomakers, J.; Mayer, H.; Lee, J.Y.; Lee, T.Y.; Jien, S.H.; Mentler, A.; Hein, T.; Huang, J.C.; Hseu, Z.Y.; Cheng, L.W.; et al. Soil aggregate breakdown and carbon release along a chronosequence of recovering landslide scars in a subtropical watershed. Catena 2018, 165, 530-536. [CrossRef]

16. da Silva, É.A.; Reinert, D.J.; Reichert, J.M.; Mallmann, M.S.; Pereira, M.A.; Pons, S.S.; Foggiato, W.S. Soil conservation management with cover crops: Effects on critical energy levels, release and dispersion of aggregates. Bragantia 2019, 78, 444-453. [CrossRef]

17. Fuller, L.G.; Goh, T.B. Stability-energy relationships and their application to aggregation studies. Can. J. Soil Sci. 1992, 72, 453-466. [CrossRef]

18. Carolino de Sá, M.A.; Lima, J.M.; Silva, M.L.N.; Junior, D. Índice de desagregação do solo baseado em energia ultra-sônica. Rev. Bras. Ciência Solo 1999, 23, 525-531. [CrossRef]

19. da Érika, A.S.; de Geraldo, C.O.; Carla, E.C.; de José, M.L.; de Laura, B.B.M.; Pedro, A.N.B. Stability of soil aggregates in Latosols and Cambisols via standard method and sonification. Afr. J. Agric. Res. 2016, 11, 3894-3903. [CrossRef]

20. Nelson, D.W.; Sommers, L.E. A Rapid and Accurate Procedure for Estimation of Organic Carbon in Soils. Proc. Indiana Acad. Sci. 1974, 84, 456-462.

21. Six, J.; Callewaert, P.; Lenders, S.; De Gryze, S.; Morris, S.J.; Gregorich, E.G.; Paul, E.A.; Paustian, K. Measuring and Understanding Carbon Storage in Afforested Soils by Physical Fractionation. Soil Sci. Soc. Am. J. 2002, 66, 1981-1987. [CrossRef]

22. Kemper, W.D.; Rosenau, R.C. Aggregate Stability and Size Distribution. Methods Soil Anal. Part 1 Phys. Mineral. Methods 1986, 5, 425-442.

23. Field, D.J.; Minasny, B.; Gaggin, M. Modelling aggregate liberation and dispersion of three soil types exposed to ultrasonic agitation. Aust. J. Soil Res. 2006, 44, 497-502. [CrossRef]

24. Vrdoljak, G.; Sposito, G. Soil aggregate hierarchy in a Brazilian oxisol. Dev. Soil Sci. 2002, 28, 197-217. [CrossRef]

25. Schmidt, M.W.I.; Rumpel, C.; Kögel-Knabner, I. Evaluation of an ultrasonic dispersion procedure to isolate primary organomineral complexes from soils. Eur. J. Soil Sci. 1999, 50, 87-94. [CrossRef]

26. Denef, K.; Six, J.; Merckx, R.; Paustian, K. Short-term effects of biological and physical forces on aggregate formation in soils with different clay mineralogy. Plant. Soil 2002, 246, 185-200. [CrossRef]

27. Oades, J.M. The role of biology in the formation, stabilization and degradation of soil structure. Geoderma 1993, 56, 377-400. [CrossRef]

28. Attou, F.; Bruand, A.; Le Bissonnais, Y. Effect of clay content and silt-clay fabric on stability of artificial aggregates. Eur. J. Soil Sci. 1998, 49, 569-577. [CrossRef]

29. Ćirić, V.; Manojlović, M.; Nešić, L.; Belić, M. Soil dry aggregate size distribution: Effects of soil type and land use. J. Soil Sci. Plant. Nutr. 2012, 12, 689-703. [CrossRef]

30. Shahabinejad, N.; Mahmoodabadi, M.; Jalalian, A.; Chavoshi, E. The fractionation of soil aggregates associated with primary particles influencing wind erosion rates in arid to semiarid environments. Geoderma 2019, 356, 113936. [CrossRef]

31. Chaney, K.; Swift, R.S. The influence of organic matter on aggregate stability in some British soils. Eur. J. Soil Sci. 1984, 35, 223-230. [CrossRef]

32. Amezketa, E.; Aragües, R.; Carranza, R.; Urgel, B. Macro- and micro-aggregate stability of soils determined by a combination of wet-sieving and laser-ray diffraction. Span. J. Agric. Res. 2003, 4, 83-94. [CrossRef] 
33. Rajeev, P.; Sumanasekera, P.R.; Sivakugan, N. Lateral variation of the vertical stress in underground mine stopes filled with granular backfills. Geotech. Geol. Eng. 2016, 34, 481-492. [CrossRef]

34. Aksakal, E.L.; Angin, I.; Sari, S. A new approach for calculating aggregate stability: Mean weight aggregate stability (MWAS). Catena 2020, 194, 104708. [CrossRef]

35. Le Bissonnais, Y. Aggregate stability and assessment of soil crustability and erodibility: I. Theory and methodology. Eur. J. Soil Sci. 1996, 47, 425-437. [CrossRef]

36. Zhu, Z.L.; Minasny, B.B.; Field, D.J. Measurement of aggregate bond energy using ultrasonic dispersion. Eur. J. Soil Sci. 2009, 60, 695-705. [CrossRef] 